\title{
Dual effect of pre-ischemic administration of TNF-alpha on myocardial infarct size
}

\author{
Thuy Tran Quang ${ }^{1}$, Raja Hatem ${ }^{2}$, Guy Rousseau ${ }^{1,3}$, Audrey-Anne Gosselin ${ }^{1}$, Erick Schampaert ${ }^{1,2}$, \\ Thierry Charron ${ }^{1,2}$
}

\author{
${ }^{1}$ Centre de Recherche, Hôpital du Sacré-Cour de Montréal, Montréal, Canada \\ ${ }^{2}$ Département de Cardiologie, Hôpital du Sacré-Cœur de Montréal, Montréal, Canada \\ ${ }^{3}$ Département de Pharmacologie, Université de Montréal, Montréal, Canada \\ Email: charront01@sympatico.ca
}

Received 26 June 2013; revised 28 July 2013; accepted 8 August 2013

Copyright (C) 2013 Thuy Tran Quang et al. This is an open access article distributed under the Creative Commons Attribution License, which permits unrestricted use, distribution, and reproduction in any medium, provided the original work is properly cited.

\section{ABSTRACT}

Tumour necrosis factor- $\alpha$ is a cytokine released during myocardial infarction. According to the literature, the effect of TNF $\alpha$ on myocardial infarction is controversial, especially when administered before the ischemic period. The deleterious effects of TNF $\alpha$ seem to be related to the triggering of apoptosis. This study has been designed to determine if different doses of TNF $\alpha$, administered before the ischemic period, have the same effect on infarct size and on activation of caspase-3 and -8, two enzymes involved in apoptosis. Four groups, using a porcine model of myocardial infarction, have been used: placebo and TNF $\alpha(0.1 \mu \mathrm{\mu g} / \mathrm{kg}$; $1 \mu \mathrm{g} / \mathrm{kg}$ and $3 \mu \mathrm{g} / \mathrm{kg}$ ). All administered 15 minutes before a 50 minutes occlusion of the left anterior descending artery. Myocardial infarct size has been determined at 3 hours of reperfusion. In a subgroup of animals, reperfusion period has been limited to 15 min to determine the activity of caspase- 3 and $\mathbf{- 8}$ by spectrofluorometry. Results indicated that infarct size is significantly smaller in groups $0.1 \mu \mathrm{g} / \mathrm{kg}$ and $1 \mu \mathrm{g} /$ $\mathrm{kg}$ as compared to the placebo group. In contrast, the $3 \mu \mathrm{g} / \mathrm{kg}$ group presented an infarct size similar to the placebo group. Activity of caspase- 3 and -8 is reduced in the ischemic region in groups 0.1 and $1 \mu \mathrm{g} / \mathrm{kg}$ as compared to the placebo group whereas activity in the $3 \mu \mathrm{g} / \mathrm{kg}$ group was similar to the placebo. The results obtained indicated that a low dose of TNF $\alpha$ administered before the ischemic period reduces infarct size, whereas the cardioprotection is lost with the high dose.

Keywords: TNF-Alpha; Myocardial Infarct Size; Protection; Apoptosis; Caspase-8

\section{INTRODUCTION}

$\mathrm{TNF} \alpha$ is a multifunctional $26 \mathrm{kDa}$ cytokine involved as a mediator of diverse physiologic and pathophysiologic events including inflammation, growth, differentiation and apoptosis. TNF $\alpha$ is thought to contribute to the development of myocardial disease, with direct correlation between plasmatic concentrations of TNF $\alpha$ and the severity and progression of heart failure [1-3]. However, recent clinical trials of anti-TNF $\alpha$ therapy for cardiovascular disease have been disappointing [4] possibly due to the dual role of TNF $\alpha$ in attenuation and aggravation of cardiac injury [5]. Indeed, some studies have shown that $\mathrm{TNF} \alpha$ was cardioprotective [6,7] whereas others have shown that TNF $\alpha$ has either no effect or possibly deleterious effects $[8,9]$.

One of the best known effect of TNF $\alpha$ is its involvement in apoptosis [1]. When activated by TNF $\alpha$, the TNF receptor 1 can activate the formation of a complex that leads to the activation of caspase-8. Nonetheless, it seems also possible that the stimulation of the TNFR1 induces the activation of enzymes involved in different cardioprotective pathways [10].

We have speculated that depending on the dose of $\mathrm{TNF} \alpha$ administered before the onset of ischemia, the effect on myocardial infarct size could be altered. To determine the mechanism by which the different doses of $\mathrm{TNF} \alpha$ can modulate the myocardium damage, activation of the caspase- 3 and -8 was measured.

\section{MATERIALS AND METHODS}

\subsection{Experimental Model}

Experiments were performed in accordance with the Canadian Council for Animal Care guidelines and were approved by the Institutional Animal Care Committee. 
Male pigs weighing from 35 to $40 \mathrm{~kg}$ were used to create a porcine model of myocardial infarction. Animals were anaesthetized with intramuscular ketamine-xylazine $(20$ $\mathrm{mg} / \mathrm{kg}$ - $2 \mathrm{mg} / \mathrm{kg}$; Wyeth Pharmaceutical, Montreal, Canada), intubated and ventilated with positive pressure ventilation (Ohmeda 7800 anaesthesia ventilator, DRE Medical, Louisville, KY) at a fraction of inspired oxygen maintained constant at 20\% - 30\%. Anaesthesia was maintained with $2 \%$ isoflurane (Abbott Laboratory, Montreal, Canada) mixed in $\mathrm{O}_{2}: \mathrm{N}_{2} \mathrm{O}(2: 1)$. The left internal jugular vein was cannulated with a $9 \mathrm{~F}$ vascular sheath and used as an access for intravenous fluid. Fluid repletion was maintained by an I.V. infusion of $0.9 \%$ sodium chloride solution at a rate of $10 \mathrm{ml} / \mathrm{kg} / \mathrm{h}$. The right carotid artery was cannulated with an $8 \mathrm{~F}$ vascular sheath and used for systemic artery pressure monitoring (8-channel polygraph; Nihon Kohden America, Foothill Ranch, CA).

\subsection{Induction of Infarct Size}

The procedure was performed via the right femoral artery with an $8 \mathrm{~F}$ vascular sheath using an $8 \mathrm{~F}$ AL1 coronary guiding catheter. An IQ angioplasty guide wire (Boston Scientific, Natick, Massachusetts, USA) was advanced in the left anterior descending (LAD), distally to the second diagonal, followed by the insertion of a $3.0 \times 15$ $\mathrm{mm}$ balloon catheter (Apex ${ }^{\mathrm{TM}}$, over-the-wire) (Boston Scientific). The balloon catheter was inflated at 4 atm for a total period of $50 \mathrm{~min}$ simulating a myocardial infarction. After this period, the balloon was deflated to allow a period of reperfusion.

After the reperfusion period (15 min or 3 hours), the catheter balloon was reinflated. The coronary angiography was performed to ensure complete occlusion of the LAD. We then injected Evan Blue via the 8F AL1 coronary guiding catheter in order to stain the heart in vivo. All pigs were euthanized, with a solution of saturated $\mathrm{KCl}$, at the end of procedures.

Four different groups were performed during that study. In the placebo group (P), normal saline was injected 15 minutes before creating the myocardial infarction period in the coronary artery just at the level of occlusion. Three different doses $(0.1 \mu \mathrm{g} / \mathrm{kg}, 1 \mu \mathrm{g} / \mathrm{kg}$ and $3 \mu \mathrm{g} / \mathrm{kg})$ of TNF were also given 15 minutes before the myocardial infarction period in the coronary artery just at the level of occlusion.

During the period of occlusion, if ventricular fibrillation, detected by ECG, occurred, we would immediately defibrillate (up to a maximum of 10 shocks) with an automated external defibrillator.

\subsection{Angiography (TIMI Frame Count)}

Angiography was performed after every important step of the procedure. Cine digital image sequences of every angiography were recorded and treated at 30 frames/s.

\subsection{Myocardial Infarct Size}

The heart was removed after 3 hours of reperfusion, frozen $\left(-80^{\circ} \mathrm{C}\right.$ for $\left.10 \mathrm{~min}\right)$, and then sliced into about 7 transverse sections of $1 \mathrm{~cm}$ thick, and placed in 2,3,5triphenyltetrazolium chloride at $37^{\circ} \mathrm{C}$ for $10 \mathrm{~min}$. The area of necrosis (I) was expressed as a percentage of the area at risk (I/AR). AR was represented as a percentage of the left ventricular $(\mathrm{LV})$, area $(\mathrm{AR} / \mathrm{LV})$. This method was described previously $[11,12]$.

\subsection{Biochemical Analysis}

For the biochemical analysis, a subgroup of pigs was performed with only $15 \mathrm{~min}$ of reperfusion. Their heart tissues were not stained, to avoid alteration of enzymatic activity under biochemical analysis. Instead, the ischemic area (AR) was separated from the nonischemic area of the myocardium (area not at risk, ANR). Each region was divided into epi-(Epi) and subendocardial (Endo) areas, defined as the upper and lower part of the myocardium. Heart tissues were snap frozen in liquid nitrogen and stored at $-80^{\circ} \mathrm{C}$.

Caspase-3 and -8 activities were measured according to the caspase-3 protocol described previously [13]. Briefly, tissues were homogenized by sonification in lysis buffer and incubated for $30 \mathrm{~min}$ on ice. The tissue homogenates were centrifuged at $4^{\circ} \mathrm{C}$ for $10 \mathrm{~min}$. Enzymatic reactions were undertaken in reaction buffer with $25 \mu \mathrm{g}$ protein and attested by the Bradford method and fluorescent substrate (Ac-DEVD-AMC or Ac-IETD-AMC, respectively, for caspase-3 and -8) (40 mmol/L). Reactions were studied after incubation in the dark for $3 \mathrm{~h}$ at $37^{\circ} \mathrm{C}$ and stopped with the addition of $0.4 \mathrm{~mol} / \mathrm{L} \mathrm{NaOH}$ and $0.4 \mathrm{~mol} / \mathrm{L}$ glycine buffer. Fluorescence was quantified by spectrofluorometry (Photon Technology International, Lawrenceville, N.J., USA) at an excitation wavelength of $365 \mathrm{~nm}$ and emission wavelength of $465 \mathrm{~nm}$ for caspase3 or $430 \mathrm{~nm}$ for caspase-8.

\subsection{Statistical Analysis}

Results are reported as mean \pm standard error of the mean (S.E.M). Comparisons were made using analysis of variance followed by Dunnett's $t$ test correction. $\mathrm{p}<0.05$ was considered statistically significant. All statistics was performed with SPSS 13.0 (SPSS, Chicago, IL).

\section{RESULTS}

Infarct size, estimated in percent of the area at risk, showed a significant reduction in the presence of the lower doses of $\mathrm{TNF} \alpha(0.1$ and $1 \mu \mathrm{g} / \mathrm{kg})$ as compared to 
the placebo group (Figure 1; $\mathrm{p}<0.05$ ). However, when the dose of $3 \mu \mathrm{g} / \mathrm{kg}$ was administered, no further difference was observed as compared to the placebo group. Area at risk, which represented around $40 \%$ of the left ventricle, shows no difference among groups. These data indicate that lower doses of TNF $\alpha$ have a beneficial effect on infarct size when administered before the ischemic period.

Activity of the caspase- 3 in the ischemic endocardial region, is significantly lower in the 0.1 and $1 \mu \mathrm{g} / \mathrm{kg}$ groups as compared to the placebo group (Figure 2). However as it is for the myocardial infarct size, activity of the caspase- 3 in the $3 \mu \mathrm{g} / \mathrm{kg}$ group is similar to the one measured in the placebo group. No significant difference was observed in the ischemic epicardial region.

In presence of TNF $\alpha$, caspase- 8 may be activated by the TNF receptor. For this reason, we have measured the activity of the caspase- 8 in the endocardial and epicardial ischemic region. Again, the results indicate a significant reduction of the activity of the caspase- 8 in the 0.1 and 1 $\mu \mathrm{g} / \mathrm{kg}$ as compared to the placebo group (Figure 3 ) in both regions. No significant difference was observed for the $3 \mu \mathrm{g} / \mathrm{kg}$ group as compared to the placebo group.

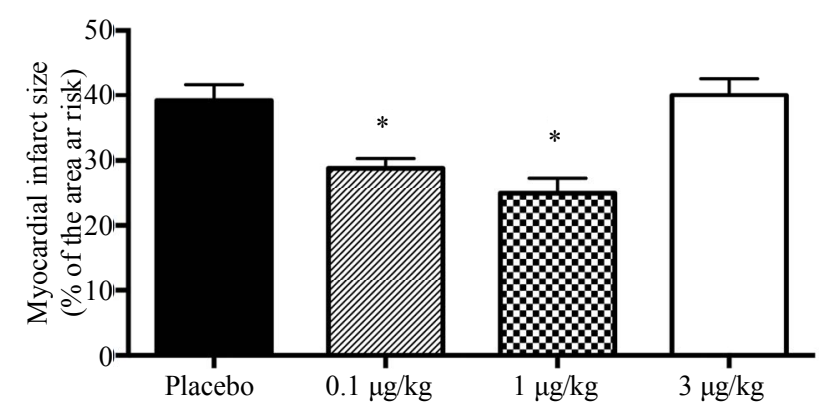

Figure 1. Myocardial infarct size (I), expressed as a percentage of the area at risk (AR), shows a significant difference between $0.1 \mu \mathrm{g} / \mathrm{kg}$ and $1 \mu \mathrm{g} / \mathrm{kg}$ as compared to placebo. No difference was observed between $3 \mu \mathrm{g} / \mathrm{kg}$ group and placebo. ${ }^{*} \mathrm{p}<0.05 \mathrm{vs}$ placebo group.

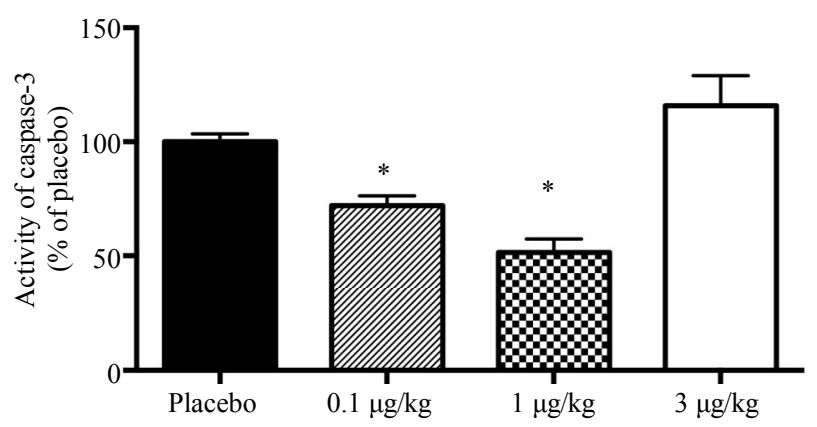

Figure 2. Caspase-3 activity in ischemic endocardial regions assessed by spectrofluorometry after 15 min reperfusion. $\mathrm{n}=4$ - 6/group: ${ }^{*} \mathrm{p}<0.05$ between the placebo and $0.1 \mu \mathrm{g} / \mathrm{kg}$ or 1 $\mu \mathrm{g} / \mathrm{kg}$ groups.

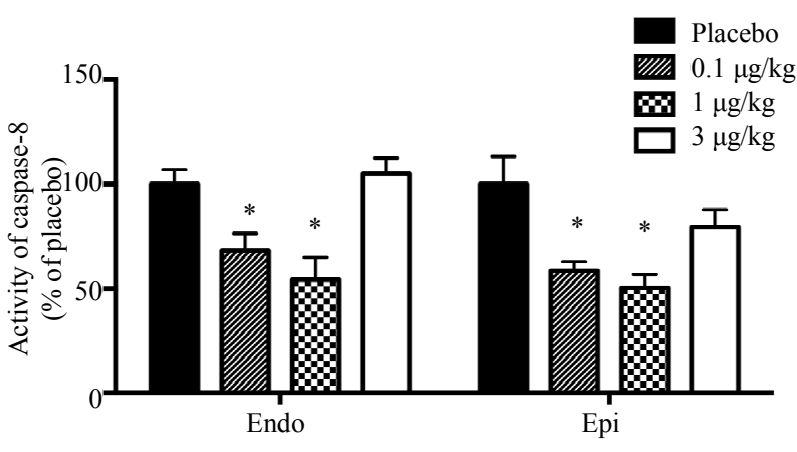

Figure 3. Caspase- 8 activity in ischemic endocardial (Endo) and epicardial (Epi) regions assessed by spectrofluorometry after 15-min reperfusion. $\mathrm{n}=4$ - 6/group: ${ }^{*} \mathrm{p}<0.05$ between the placebo and $0.1 \mu \mathrm{g} / \mathrm{kg}$ or $1 \mu \mathrm{g} / \mathrm{kg}$ groups.

\section{DISCUSSION}

Our data indicate that pretreatment with $\mathrm{TNF} \alpha$ results in a significant reduction of infarct size when low doses $(0.1$ and $1 \mu \mathrm{g} / \mathrm{kg})$ are used. In contrast, higher dose of $\mathrm{TNF} \alpha(3 \mu \mathrm{g} / \mathrm{kg})$ did not afford any protection as compared to our placebo group. The protection is probably related to a lower activity of the caspase- 3 and -8 , known to be involved in apoptosis.

The effects of TNF $\alpha$ on myocardial infarct size have been controversial. For example, when TNF $\alpha$ is reduced before ischemia with the use of a TNF $\alpha$ antibody, studies indicated a significant reduction of infarct size [14,15]. However, when the level of TNF $\alpha$ is modulated by soluble TNF receptor, some studies observed a significant reduction of infarct size [16] whereas others detected no significant effects [8]. Using TNF $\alpha \mathrm{KO}$ mice, Maekawa et al. observed a reduction in infarct size [9] but in contrast, KO of TNF p75 receptor induces a loss in cardioprotection, suggesting a protective role of $\mathrm{TNF} \alpha$ in some circumstances. According to the results obtained by Deuchar et al. [6], administration of different doses of $\mathrm{TNF} \alpha$, administered 24-min before the ischemia results in an inverse bell shape effect, maximal protection observed with the dosage of $0.1 \mu \mathrm{g} / \mathrm{kg}$ whereas with dosage of 0.2 $\mu \mathrm{g} / \mathrm{kg}$ or $4 \mu \mathrm{g} / \mathrm{kg}$ results in an infarct size similar to placebo group. These results are similar to the one observed with the present study and suggest, as proposed by Lecour et al. [17], that the dosage and the timing are critical for the protection afforded by $\mathrm{TNF} \alpha$. The difference in the effect of the dosage may be due to the species used (rat against pig) as well as the way the TNF $\alpha$ was administered. In the study of Deuchar et al. TNF $\alpha$ was injected 24 min before the ischemic period i.v. whereas in the present protocol, TNF $\alpha$ was administered i.c. $15 \mathrm{~min}$ before the occlusion of the coronary artery.

These results also reflect the duality of the TNF $\alpha$ effects in the context of an ischemia-reperfusion protocol as reported by Duran [18]. Different cell types, such as 
myocytes or vascular smooth muscle cells, can synthesize TNF $\alpha$. In normal conditions the level of synthesis of $\mathrm{TNF} \alpha$ is low but increases rapidly during ischemia/reperfusion [19]. These levels then diminish during the first hours of reperfusion [20]. TNF $\alpha$ exerts its effects through 2 different receptors: TNFR1 and TNFR2. The binding of the TNF $\alpha$ to the TNFR1 induces the trimerization of the receptor and promotes the dissociation of the silencer death domain from the receptor. The death domain of the activated receptor recruits the TNFR1-associated death domain (TRADD), RIP1 and TRAF2, which then becomes modified and dissociate from TNFR1. The released death domain of TRADD is now able to bind to Fas-associated protein with death domain, resulting in the activation of the caspase- 8 and then caspase- 3 [1]. In contrast, TNFR1 can also activate the NF-kB pathway, through the phosphorylation and ubiquity-nation of different proteins that bind the TNFR1-TRADDTRAF-RIP1 complex. When NF-kB is activated, its translocation to the nucleus mediates the transcription of different proteins such as $\mathrm{TNF} \alpha$.

TNFR1 can also activate other signaling pathway including c-Jun N-terminal kinase (JNK), p38 mitogenactivated protein kinase and PI3k/Akt [10]. These enzymes have been identified to be members of two important signaling pathways that can induce cardioprotection: the RISK [21] and SAFE pathways [22]. Our data indicate that the activity of both caspase- 3 and -8 is elevated in the control and $3 \mu \mathrm{g} / \mathrm{kg}$ groups whereas the activation is significantly less in the $0.1 \mu \mathrm{g} / \mathrm{kg}$ and $1 \mu \mathrm{g} /$ $\mathrm{kg}$ groups. This difference in the activation suggests that the lower doses of TNF $\alpha$ can induce the activation of the protective pathways, when activated before the ischemic period, whereas other pathways are activated with the higher doses. The difference in the myocardial infarct size between placebo and the other groups $(0.1 \mu \mathrm{g} / \mathrm{kg}$ and $1 \mu \mathrm{g} / \mathrm{kg}$ ) can be due to the activation of the protective pathway induced by the activation of the TNFR1 before the ischemic period, but other experiments are needed to confirm this hypothesis.

We have measured the activity of the caspase- 3 and -8 after 15 minutes of reperfusion because previous data indicate that this activity is high during the first minute of reperfusion to reduce, and it is also basal at 5 hours of reperfusion [23].

One major limitation in this protocol is the availability of antibodies to perform biochemical analysis that is compatible with a porcine model. For this reason, we have been limited in the number of measures that can be performed.

In conclusion, we have documented that low doses of $\mathrm{TNF} \alpha$ can induce cardioprotection when administered before the ischemic period. However, with high doses, this protection is lost probably due to the activation of the caspase- 3 and -8 .

\section{ACKNOWLEDGEMENTS}

This work was supported by the Centre de recherche, Hôpital du SacréCoeur de Montréal and Fonds de la recherche du Québec-Santé (FRQS). We thank Louis Chiocchio and Caroline Bouchard for their help in animal care.

\section{REFERENCES}

[1] Kleinbongard, P., Schulz, R. and Heusch, G. (2011) TNFalpha in myocardial ischemia/reperfusion, remodeling and heart failure. Heart Failure Reviews, 16, 46-69.

[2] Levine, B., et al. (1990) Elevated circulating levels of tumor necrosis factor in severe chronic heart failure. The New England Journal of Medicine, 323, 236-241. doi:10.1056/NEJM199007263230405

[3] Przyklenk, K., et al. (1993) Regional ischemic "preconditioning" protects remote virgin myocardium from subsequent sustained coronary occlusion. Circulation, 87, 893899. doi:10.1161/01.CIR.87.3.893

[4] Mann, D.L. (2002) Inflammatory mediators and the failing heart: Past, present, and the foreseeable future. Circulation Research, 91, 988-998. doi:10.1161/01.RES.0000043825.01705.1B

[5] Sack, M.N. and Yellon, D.M. (2003) Insulin therapy as an adjunct to reperfusion after acute coronary ischemia: A proposed direct myocardial cell survival effect independent of metabolic modulation. Journal of the American College of Cardiology, 41, 1404-1407. doi:10.1016/S0735-1097(03)00164-5

[6] Deuchar, G.A., Opie, L.H. and Lecour, S. (2007) TNFalpha is required to confer protection in an in vivo model of classical ischaemic preconditioning. Life Science, 80, 1686-1691. doi:10.1016/j.lfs.2007.01.040

[7] Lecour, S., Rochette, L. and Opie, L. (2005) Free radicals trigger TNF alpha-induced cardioprotection. Cardiovascular Research, 65, 239-243.

doi:10.1016/j.cardiores.2004.10.003

[8] Kaloustian, S., et al. (2009) Tumor necrosis factor-alpha participates in apoptosis in the limbic system after myocardial infarction. Apoptosis, 14, 1308-1316. doi:10.1007/s10495-009-0395-x

[9] Maekawa, N., et al. (2002) Improved myocardial ische$\mathrm{mia} /$ reperfusion injury in mice lacking tumor necrosis factor-alpha. Journal of the American College of Cardiology, 39, 1229-1235. doi:10.1016/S0735-1097(02)01738-2

[10] Bradley, J.R. (2008) TNF-mediated inflammatory disease. Journal of Pathology, 214, 149-160. doi: $10.1002 /$ path. 2287

[11] Boucher, M., et al. (2002) Alterations of beta-adrenoceptor responsiveness in postischemic myocardium after $72 \mathrm{~h}$ of reperfusion. European Journal of Pharmacology, 495, 185-191. doi:10.1016/j.ejphar.2004.05.040

[12] Wann, B.P., et al. (2006) Apoptosis detected in the amygdala following myocardial infarction in the rat. Biological 
Psychiatry, 59, 430-433. doi:10.1016/j.biopsych.2005.07.018

[13] Boucher, M., et al. (2006) Reduction of apoptosis in the amygdala by an A2A adenosine receptor agonist following myocardial infarction. Apoptosis, 11, 1067-1074. doi:10.1007/s10495-006-6313-6

[14] Belosjorow, S., et al. (2003) TNF-a antibodies are as effective as ischemic preconditioning in reducing infarct size in rabbits. American Journal of Physiology, 284, H927-H930.

[15] Gu, Q., et al. (2006) Inhibition of TNF-alpha reduces myocardial injury and proinflammatory pathways following ischemia-reperfusion in the dog. Journal of Cardiovascular Pharmacology, 48, 320-328. doi:10.1097/01.fjc.0000250079.46526.38

[16] Sugano, M., et al. (2004) In vivo transfer of soluble TNFalpha receptor 1 gene improves cardiac function and reduces infarct size after myocardial infarction in rats. FASEB Journal, 18, 911-913.

[17] Lecour, S., et al. (2002) Identification of a novel role for sphingolipid signaling in TNF alpha and ischemic preconditioning mediated cardioprotection. Journal of Molecular and Cellular Cardiology, 34, 509-518. doi:10.1006/jmcc.2002.1533

[18] Duran, W.N. (2008) The double-edge sword of TNF-alpha in ischemia-reperfusion injury. American Journal of
Physiology-Heart and Circulatory Physiology, 295, H2221-H2222. doi:10.1152/ajpheart.01050.2008

[19] Reil, J.C., et al. (2007) Insights from knock-out models concerning postischemic release of TNFalpha from isolated mouse hearts. Journal of Molecular and Cellular Cardiology, 42, 133-141. doi:10.1016/j.yjmcc.2006.09.020

[20] McVey, M., Perrone, M.H. and Clark, K.L. (1999) Does tumor necrosis factor-alpha (TNF-alpha) contribute to myocardial reperfusion injury in anesthetized rats? General Pharmacology, 32, 41-45. doi:10.1016/S0306-3623(98)00050-0

[21] Hausenloy, D.J., Tsang, A. and Yellon, D.M. (2005) The reperfusion injury salvage kinase pathway: A common target for both ischemic preconditioning and postconditioning. Trends in Cardiovascular Medicine, 15, 69-75. doi:10.1016/j.tcm.2005.03.001

[22] Lecour, S. (2009) Multiple protective pathways against reperfusion injury: A SAFE path without Aktion? Journal of Molecular and Cellular Cardiology, 46, 607-609. doi:10.1016/j.yimcc.2009.01.003

[23] Boucher, M., et al. (2004) Post-ischemic cardioprotection by A2A adenosine receptors: Dependent of phosphatidylinositol 3-kinase pathway. Journal of Cardiovascular Pharmacology, 43, 416-422. doi:10.1097/00005344-200403000-00013 